Published in final edited form as:

J Acquir Immune Defic Syndr. 2014 February 1; 65(2): e50-e57. doi:10.1097/QAI.0b013e3182a0a050.

\title{
Effect of Text Messaging to Deter Early Resumption of Sexual Activity after Male Circumcision for HIV Prevention: A Randomized Controlled Trial
}

Thomas A. ODENY, MBChB, MPH, ${ }^{1,2}$, Robert C. BAILEY, PhD, MPH, ${ }^{3}$, Elizabeth A. BUKUSI, MBChB, MMed, MPH, PhD ${ }^{2,4,5}$, Jane M. SIMONI, PhD ${ }^{4,6}$, Kenneth A. TAPIA, MS ${ }^{4,8}$, Krista YUHAS, MS ${ }^{4,8}$, King K. HOLMES, MD, PhD ${ }^{4,7,8}$, and R. Scott MCCLELLAND, MD, MPH ${ }^{1,4,7,8}$ ${ }^{1}$ Department of Epidemiology, University of Washington, Seattle, WA, USA

${ }^{2}$ Kenya Medical Research Institute (KEMRI), Nairobi, Kenya

${ }^{3}$ Chicago Developmental Center for AIDS Research, University of Illinois at Chicago

${ }^{4}$ Department of Global Health, University of Washington, Seattle, WA, USA

${ }^{5}$ Department of Obstetrics and Gynecology, University of Washington, Seattle, WA, USA

${ }^{6}$ Department of Psychology, University of Washington, Seattle, WA, USA

${ }^{7}$ Department of Medicine, University of Washington, Seattle, WA, USA

${ }^{8}$ Center for AIDS and STD, University of Washington, Seattle, WA, USA

\begin{abstract}
BACKGROUND-Resumption of sex before complete wound healing after male circumcision may increase risk of post-operative surgical complications, and HIV acquisition and transmission. We aimed to determine the effect of text messaging to deter resumption of sex before 42 days post-circumcision.
\end{abstract}

METHODS-We conducted a randomized trial where men $>18$ years old who owned mobile phones and had just undergone circumcision were randomized to receive a series of text messages

Correspondence and requests for reprints to: R. Scott McClelland, MD, MPH, Box 359909, 325 Ninth Avenue, Seattle, WA 98104, USA, Telephone: (206) 543-4278, Fax: (206) 543-4818, mcclell@u.washington.edu.

Note: These data were previously presented in part at the 16th International Conference on AIDS and STIs in Africa, Addis Ababa, Ethiopia, December 4-8, 2011 (abstract THLB0103).

Conflicts of Interest

All authors report that they have no conflicts of interest related to this work.

List of Supplemental Digital Content

Supplemental Digital Content 1. Table showing baseline characteristics of participants without outcome data (lost to follow-up) versus those retained. pdf

Authors' contributions

TAO participated in conceptualizing, designing, and conducting the study, analysing and interpreting the data, and drafting the manuscript. RCB originally conceived of the study. RCB, KKH and RSM further conceptualized the study, participated in study design, provided mentorship during study conduct, and made substantial contributions to interpretation of the results and drafting of the manuscript. EB and JS participated in study design, provided mentorship during study conduct, contributed to data interpretation, and reviewed the manuscript. KT and KY contributed to statistical analysis, data interpretation, and drafting of the manuscript. All authors read and approved the final manuscript.

This is a PDF file of an unedited manuscript that has been accepted for publication. As a service to our customers we are providing this early version of the manuscript. The manuscript will undergo copyediting, typesetting, and review of the resulting proof before it is published in its final citable form. Please note that during the production process errors may be discovered which could affect the content, and all legal disclaimers that apply to the journal pertain. 
( $n=600)$ or usual care $(n=600)$. The primary outcome was self-reported resumption of sex before 42 days.

RESULTS-Sex before 42 days was reported by 139/491 (28.3\%) men in the intervention group and $124 / 493(25.2 \%$ ) in the control group (relative risk=1.13, 95\% CI 0.91-1.38, p=0.3). Men were more likely to resume early if they were married or had a live-in sexual partner (adjusted relative risk [aRR] 1.57, 95\% CI 1.18-2.08, $\mathrm{p}<0.01)$; in the month before circumcision had one (aRR 1.50, 95\% CI 1.07-2.12, $\mathrm{p}=0.02)$ or $>1$ (aRR 1.81, 95\% CI 1.24-2.66, $\mathrm{p}<0.01$ ) sexual partner(s); had primary school or lower education (aRR 1.62, 95\% CI 1.33-1.97, $\mathrm{p}<0.001$ ); were employed (aRR 1.35, 95\% CI 1.05-1.72, $\mathrm{p}=0.02$ ); or were $21-30$ years old (aRR $1.58,95 \%$ CI $1.01-2.47, \mathrm{p}=0.05) ; 31-40$ (aRR 1.91, 95\% CI 1.18-3.09, $\mathrm{p}<0.01)$ or $>40$ years old $(\mathrm{aRR} 1.76,95 \%$ CI 1.04-2.97, $\mathrm{p}=0.03$ ) compared to $<21$ years old.

CONCLUSIONS-Text messaging as used in this trial did not reduce early resumption of sex after circumcision. We identified key risk factors for early resumption that need to be considered in circumcision programs.

\section{Keywords}

SMS text messaging; mobile phone; male circumcision; sexual behavior; HIV prevention; Africa

\section{INTRODUCTION}

Efforts are under way to greatly expand medical male circumcision (MC) for HIV prevention in sub-Saharan Africa. ${ }^{1-6}$ Male circumcision reduces the risk of female-to-male HIV transmission by about $60 \%,{ }^{1-3}$ and may reduce the risk of male-to-female transmission by $46 \% .^{7}$ Resumption of sexual activity during the healing period may increase the risk for HIV acquisition in HIV-negative men. ${ }^{8}$ Similarly, in HIV-positive men, early resumption of sexual activity may increase risk for transmission to sex partners. ${ }^{9,10}$ Following MC, men are advised to abstain from sexual activity for at least six weeks to allow for complete wound healing. ${ }^{11,12}$ Earlier resumption of sexual activity may also increase the risk of postoperative surgical complications. ${ }^{13}$ Despite these risks, the proportion of circumcised men reporting resumption of sexual activity before the end of the recommended six-week abstinence period has been high. For example, approximately $31 \%$ of circumcised men reported resuming sex early in Kenya, and $24 \%$ in Zambia. ${ }^{10,14}$

The low cost of mobile phone communication in resource-limited settings presents a unique avenue to potentially change behavior, improve health outcomes, and magnify the impact of public health interventions. ${ }^{15}$ During the past decade, access to mobile phones has increased substantially in developing countries. The International Telecommunications Union estimates that approximately $79 \%$ of the population in developing countries has access to a mobile phone. The use of mobile phone technology to complement public health interventions (mHealth) ${ }^{16,17}$ is gaining traction across Africa, especially as part of larger health communication strategies. Although no empirical data were available to support it, the Joint United Nations Programme on HIV/AIDS (UNAIDS) recommends the use of short messaging service (SMS) as part of strategic communication towards accelerating the scaleup of MC and providing high-quality services. ${ }^{18,19}$ Mobile phones are also acceptable for providing HIV-related information. ${ }^{20}$ Text messages have been effective in varied settings for a variety of interventions, including increasing adherence to antiretroviral treatment, 21,22 reducing HIV risk behaviors ${ }^{23}$, improving uptake of vaccination, ${ }^{24,25}$ promoting smoking cessation, ${ }^{26}$ and shortening notification times for infant HIV test results. ${ }^{27}$ We previously reported that text messaging improves attendance at post-operative clinic appointments after male circumcision for HIV prevention. ${ }^{28}$ However, SMS interventions per se have not been 
universally successful. For example, the Cameroon Mobile Phone SMS (CAMPS) trial found no effect of text messaging on antiretroviral adherence. ${ }^{29}$

Our aim was to determine whether a series of one-way educational and reminder SMS messages could significantly reduce the frequency of self-reported resumption of sexual activity before 42 days after MC compared to a control condition of usual care.

\section{METHODS}

\section{Trial design and participants}

We conducted a two-arm, parallel, randomized controlled trial conducted at 12 sites in Nyanza province, Kenya. There were two main endpoints: 1) attendance at the scheduled seven-day post-operative clinic visit, and 2) self-reported resumption of sexual activity before 42 days after MC. Results related to the first endpoint have been reported elsewhere. ${ }^{28}$

Men who had undergone MC were approached during the 30-minute post-circumcision recovery period and assessed for eligibility. Those who were at least 18 years old, owned mobile phones, had the phone in their possession at enrolment, and were willing to respond to a phone interview after six weeks were randomized in a 1:1 ratio to receive either text messages or usual care.

\section{Randomisation and masking}

An independent biostatistician generated a block randomization scheme with variable block sizes of 4 to 16 participants, stratified by clinic. Consecutive, sequentially-numbered, sealed, opaque envelopes were used to assign participants to study arms. Because the intervention arms included receiving SMS versus not receiving study SMS messages, participants were not masked to study group assignment. However, clinic staff members were unaware of the participants' group assignments.

\section{Procedures}

At enrolment, baseline characteristics and participant mobile phone numbers were collected. After randomization, participants sent a registration text message containing the study site and participant identification number. For those in the SMS arm, the registration message also included the preferred time of day and language (English, Kiswahili or Dholuo) for receiving intervention messages. All participants received US $\$ 0.25$ worth of airtime as reimbursement to cover the cost of the registration SMS. Usual care consisted of a 'minimum package' that included HIV testing and counselling, screening and treatment for sexually transmitted infections, condom promotion and provision, risk reduction and safe sex counselling, the MC procedure, and post-operative review seven days after surgery. ${ }^{30}$

To automate the SMS intervention, we used RapidSMS, an open source framework for SMS applications. ${ }^{31}$ Text messages were sent at the time and in the language preferred by the participant. For the first seven days, messages were sent once each day. Thereafter, messages were sent on days $8,14,21,28,35,41$, and 42 post-procedure. Table 1 summarizes the text message protocol. The message timing schedule was adapted from a pilot study conducted to assess the acceptability of the messages among circumcised men in Nyanza province, Kenya. After 42 days, study staff called participants in both randomization arms to conduct a brief structured interview. Participants were asked whether they had resumed sexual activity, which was defined to include sexual intercourse or masturbation per the Kenya MC guidelines. ${ }^{32}$ For those who reported sexual activity, additional questions were asked to determine the number of sexual partners, total number of sex acts, and number 
of sex acts with a condom. If participants were unreachable by phone on our first attempt, we tried calling again once each day for one week. Those who could still not be reached were considered lost to follow-up.

\section{Ethical review}

All participants provided written informed consent. This trial was approved by the Human Subjects Division at the University of Washington, the Ethical Review Committee of the Kenya Medical Research Institute, and Institutional Review Board \#3 at the University of Illinois at Chicago.

\section{Statistical analysis}

The primary outcome was the proportion of men reporting early resumption of sex (i.e. before 42 days post-MC). We assumed that $22.5 \%$ of men in the control group would report early resumption. ${ }^{1}$ To have at least $80 \%$ power to detect a reduction to $15 \%$ or less reporting early resumption of sex in the SMS group, and allowing for $11 \%$ loss to follow-up at 42 days, we enrolled 600 men in each arm.

We assessed the effect of study arm on the primary outcome using relative risk regression (Poisson model, robust error variance). ${ }^{33}$ We performed 1) a complete case analysis that included only men with follow-up at the end of the 42-day period and 2) a multiple imputation by chained equations analysis that imputed missing outcome data under missingat-random assumptions, a method considered superior to complete case analysis in the presence of missing outcome data. ${ }^{34}$ The multiple imputation analysis used baseline covariate information (age, ethnicity, employment status, education level, marital status, age at first sex, number of sex partners in the month prior to $\mathrm{MC}$, source of referral to $\mathrm{MC}$ clinic, whether HIV testing was done before $\mathrm{MC}$, whether condoms were issued after $\mathrm{MC}$, and cadre of the health worker who performed the MC procedure) and allowed us to use data from all 1200 men. Lastly, we performed a sensitivity analysis that examined the composite outcome of early resumption or missing outcome.

We conducted secondary analyses using the complete case dataset. We used adjusted relative risk regression to estimate associations between other covariates and early selfreported resumption of sex. Variables included in this model were selected based on known or suspected risk factors for early resumption of sex and included: study arm, age, marital status, number of sex partners in the month prior to MC, level of education, and employment status. Secondary analyses were repeated using the imputed dataset.

We compared time to self-reported resumption of sex (in weeks from time of circumcision) by study arm using Kaplan-Meier analysis and a log-rank test. We also compared the number of sex partners, total sex acts, and unprotected sex acts by study arm, and compared using Wilcoxon rank sum tests. Among men who resumed early, the proportions of men reporting any unprotected acts versus using protection for all sex acts in each arm was compared using relative risk regression.

All tests were two-sided at the 5\% significance level. Stata IC v10 was used for analysis. Multiple imputation used the Stata "ice" package with five imputed datasets. ${ }^{35,36}$

\section{Role of the funding source}

The sponsors had no role in study design, data collection, analysis, interpretation, writing of the report, or decision to submit the manuscript for publication. The corresponding author had full access to all data and had final responsibility for the decision to submit for publication. 


\section{RESULTS}

We assessed 3,572 men for eligibility at 12 sites in Nyanza province, Kenya, between September 2010 and April 2011. Of these, we randomly assigned 1,200 to receive either the intervention or usual care (figure 1). Data on self-reported resumption of sex before 42 days were available for $491(81.8 \%)$ and $493(82.2 \%)$ men in the SMS and usual care groups, respectively.

Participant characteristics were similar at baseline in SMS and usual care groups ${ }^{28}$ and remained similar when restricted to only participants with non-missing outcome data (table 2). However, several baseline characteristics of participants with endpoint data differed from the baseline characteristics of participants lost to follow-up (see Table, Supplemental Digital Content 1). Specifically, participants who were lost were significantly younger, less likely to be employed, and spent more time traveling to clinic. Greater loss to follow-up was also significantly associated with having fewer sex partners in the month prior to $\mathrm{MC}$, fewer years of education, unmarried status, and more likely to be referred to MC by a friend.

In the complete case analysis, self-reported resumption of sex before 42 days postcircumcision was reported by 139/491 (28.3\%) men in the SMS group and 124/493 (25.2\%) men in the control group (relative risk for early resumption $=1.13,95 \%$ CI $0.91-1.38 ; \mathrm{p}=0.3$ ). Results were essentially unchanged when multiple imputation methods were used to account for losses to follow-up at day 42 ( $R R=1.13,95 \%$ CI 0.92-1.38, $\mathrm{p}=0.2)$. Similarly, when we examined a composite outcome of resumed or missing outcome, the proportion of men who resumed sex in the SMS group remained slightly higher $(248 / 600 ; 41.3 \%)$ than in the control group $(231 / 600 ; 38.5 \%)$, but again the difference was not statistically significant $(\mathrm{RR}=1.07$, 95\% CI 0.93-1.23, $\mathrm{p}=0.3$ ).

In the complete case analysis, men were more likely to report early resumption of sex (table 3 ) if they were married or had a live-in sexual partner (adjusted relative risk [aRR] 1.57, 95\% CI 1.18-2.08, p<0.01); had one (aRR 1.50, 95\% CI 1.07-2.12, $\mathrm{p}=0.02$ ) or $>1$ (aRR 1.81, 95\% CI 1.24-2.66, $\mathrm{p}<0.01$ ) sexual partner(s) in the month prior to MC; had primary school or lower education level (aRR 1.62, 95\% CI 1.33-1.97, $\mathrm{p}<0.001$ ); or were employed (aRR $1.35,95 \%$ CI 1.05-1.72, $\mathrm{p}=0.02$ ). Compared to men less than 21 years old, there was higher likelihood of early resumption of sex in men 21-30 (aRR 1.58, 95\% CI 1.01-2.47, $\mathrm{p}=0.05$ ); $31-40$ (aRR 1.91, 95\% CI 1.18-3.09, p<0.01); and >40 years old (aRR 1.76, 95\% CI $1.04-2.97, \mathrm{p}=0.03)$.

A Kaplan-Meier plot showing the cumulative incidence of self-reported resumption of sex is shown in figure 2 . There was no significant difference between the groups in time to resumption of sex (log-rank test, $\mathrm{p}=0.3$ ). Of the 263 men who reported resuming sex early, $236(90 \%)$ reported their first sexual activity after 28 days or later.

The median number of sexual partners within 42 days after MC did not differ between the SMS and control arms (median=1, IQR=1-1 versus median=1, IQR=1-1, $\mathrm{p}=0.7$ ). Similarly, the median number of sex acts was the same in the intervention and control arms (median=0, $\mathrm{IQR}=0-1$ versus median $=0, \mathrm{IQR}=0-0, \mathrm{p}=0.3$ ).

While the median number of unprotected sex acts was zero in both intervention and control groups, the distributions in the two groups differed significantly (Wilcoxon rank-sum text, $\mathrm{p}=0.007$ ). We explored this finding further by comparing risk of any unprotected sex in analyses restricted to the subgroup of men who reported early resumption of sex. In this subgroup, 87/135 (64.4\%) in the SMS arm and 58/122 (47.5\%) in the control arm reported unprotected sex. Data on number of sex acts, number of unprotected sex acts, and number of sex partners for six men (four SMS arm, two control arm) who reported resuming sex were 
missing and were excluded. After adjusting for age, employment, marital status, age at first sex, educational level, source of referral to the clinic, number of sex partners in the month prior to MC, and whether condoms were issued at the clinic after MC, men in the SMS arm remained significantly more likely to report unprotected sex within the first 42 days after MC (aRR 1.30, 95\% CI $1.05-1.61, \mathrm{p}=0.02$ ). Men were also more likely to report unprotected sex during this period if they were married (aRR 1.61, 95\% CI 1.05-2.48, $\mathrm{p}=0.03$ ), or were referred to the clinic from a voluntary counselling and testing centre (aRR $1.96,95 \%$ CI $1.25-3.10, \mathrm{p}<0.01)$.

\section{DISCUSSION}

In this large randomized trial in Kenya, SMS messages with educational and reminder content sent to men after MC did not reduce self-reported resumption of sexual activity before the end of the 42-day prescribed period of abstinence. To our knowledge, this is the first trial to assess the effect of text messages on resumption of sex after MC for HIV prevention. Although the intervention was not successful, additional analyses of data from this trial provide new insights about factors associated with early resumption of sexual activity after MC.

There is a growing body of evidence that text message reminders can increase attendance at clinic appointments. ${ }^{37-39}$ Similarly, we have shown improvement in clinic attendance after male circumcision. ${ }^{28}$ Our SMS intervention did not lead to delayed self-reported resumption of sexual intercourse as intended, and might have been more successful if it had been supported by formative qualitative research grounded in a behavioural change framework. ${ }^{40-42}$ Other SMS interventions have also provided conflicting results. For example, the Cameroon Mobile Phone SMS (CAMPS) trial found no effect of text messaging on antiretroviral adherence. ${ }^{29}$ This finding is somewhat surprising, as two randomized trials in Kenya had demonstrated a significant benefit. ${ }^{21,22}$ The success of SMS interventions may be related to specifics of the intervention and to contextual factors. Designing future interventions with a firm basis in behavioral theory may make it easier to predict where, when, and how SMS interventions are likely to be successful.

Our study did not formally assess acceptability of the intervention, or whether participants would have preferred more interactive two-way text messaging. In other studies such as the WelTel Kenya1 trial, ${ }^{43}$ two-way messaging was associated with significant improvements in antiretroviral adherence and virologic suppression. Further support for the acceptability of two-way messaging comes from the CAMPS trial where half of participant responses were messages of gratitude. ${ }^{44}$

The high overall proportion who reported resuming sex within 42 days (26.7\%) was similar to the proportion in a randomized trial population in South Africa, ${ }^{1}$ and in observational studies in Kenya $\left(31 \%{ }^{14} ; 37.7 \%{ }^{45}\right.$ ) and Zambia $(24 \%) .{ }^{10}$ In contrast, fewer men reported resumption of sex earlier than 42 days in the randomized trials of MC for HIV prevention in Kisumu, Kenya (3.9\%) and Rakai, Uganda (5.4\%). ${ }^{8}$ This striking difference may be explained by the intense, individually tailored risk-reduction counselling given to participants in Kisumu and Rakai at each study visit. In contrast, the South African Trial did not include any counselling during the 42-day abstinence period, and MC programs ongoing today typically include counselling only at the time of circumcision.

In our study, the great majority (90\%) of participants who resumed sex early did so more than 28 days after MC. This may be related to men's own perception of completion of wound healing. In a separate study by our group, more than $70 \%$ of men had completely healed wounds by the end of the fourth week post-circumcision. ${ }^{46}$ Of note, the SMS 
message we sent on day 28 advised men not to have sex until they were fully healed. If men in the intervention arm perceived their wounds to be fully healed by day 28 , then this message may have inadvertently supported a decision to resume sex before 42 days for this group. Also, none of the messages explicitly told men to delay sex until six weeks, except the day 8 message. The 41 day message may have tacitly alluded to sex or may have seemed to encourage resumption by use of the word "if" instead of "when". Future interventions aimed at delaying resumption of sex should focus on risk reduction throughout the risk period after MC, and specifically encourage abstinence until after day 42 regardless of the appearance of the wound. In this regard, messages between days 28 and 42 should address the issue of not assuming that the wound is healed based on self-assessment. While many men have achieved complete wound healing by 4 weeks, nearly one-third are not completely healed at this point. ${ }^{13,47}$ Moreover, men's own assessment of wound healing agrees with that of a clinician only $65 \%$ of the time. ${ }^{45}$ As such, what men perceive as healed may not be "fully healed". In the absence of follow-up visits for certification of wound healing by a clinician, the conservative period of a minimum of six weeks allows for the majority of wounds to heal.

This study included a number of limitations. First, men less than 18 years old and those who did not possess phones were excluded, limiting generalizability of our results. However, access to mobile phones is increasing substantially in Kenya. Between December 2011 and March 2012, mobile phone subscribers increased from 28.08 million to 29.2 million. ${ }^{48}$ Second, we recognize that resumption of sex before 42 days was a self-reported outcome. In this context, our results may be affected by social desirability bias, with under-reporting of early resumption of sex. If men were worried about sexual performance after MC, they may also have over-reported resumption of sex. Third, we did not ask men in the intervention arm if they received the text messages, or how many messages were received. It is possible that some may not have received the SMS due to changing phone numbers, network failures, or other reasons. Fourth, we did not collect data on phone sharing by study participants. Some men may share phones, and could have missed the SMS messages as a result. Fifth, we did not specifically test for literacy in participants. However, only 30 (2.5\%) study participants reported having no education. Nonetheless, we recognize that failure to receive messages, sharing of phones, and challenges with literacy may have contributed to the lack of efficacy observed in this trial. Finally, the $18 \%$ loss to follow-up at day 42 was higher than anticipated. Being unreachable by phone may have been associated with failure to receive intervention messages for men in the SMS arm.

Despite these limitations, our study identified important risk factors for early resumption of sexual activity after MC, providing guidance to inform the development of interventions to improve outcomes after adult MC for HIV prevention. Specifically, and consistent with previous studies by Herman-Rolof et al. ${ }^{14}$ and Odoyo-June et al., ${ }^{45}$ we found that early resumption of sex was associated with being married or living with a sexual partner, reporting one or more sexual partners in the month prior to MC, older age, employment, and education level. Men living with sexual partners likely have greater opportunity to resume sex, may simply feel more comfortable resuming sex earlier than advised, or find it harder to abstain. Involvement of female partners in scale-up of MC might address this problem. ${ }^{49,50}$

Men with primary or lower level of education were significantly more likely to report early resumption of sex. It is possible that such men were less likely to understand the postoperative care instructions. Additional education and counselling for this group should be considered as MC programs continue to expand. Lower health literacy is associated with poor HIV treatment adherence. ${ }^{51,52}$ In-depth qualitative studies would be helpful for understanding the reasons for early resumption of sex, and could inform the development of interventions aimed at promoting sexual abstinence until 42 days after MC. 
While we did not find a reduction in early self-reported resumption of sex following MC with this SMS intervention, these data highlight the need for further research using low-cost technologies to reduce early resumption of sexual activity and maximize the benefits of MC for HIV prevention. Where SMS interventions have been successful in promoting antiretroviral adherence and smoking cessation, the lingering question has been why they worked. ${ }^{53,54}$ Future interventions with mobile phone technologies could be strengthened by developing a foundation based in behavioural theory to explain the mechanism by which they might reduce early resumption of sex following MC.

As MC programs continue to expand across sub-Saharan Africa, resumption of sex before 42 days after the procedure will continue to be an issue to address, and a possible threat to significant reduction in HIV incidence. Our findings point to several key risk factors for early self-reported resumption of sex that MC programs should take into account as they develop interventions to address this issue.

\title{
Supplementary Material
}

Refer to Web version on PubMed Central for supplementary material.

\section{Acknowledgments}

\begin{abstract}
Source of Funding
This study was funded by the University of Washington International AIDS Research Training Program, which is supported by the Fogarty International Center (NIH 5D43-TW000007). Additional support for the trial was provided by the Biometrics, International, and Socio-behavioral and Prevention Research Cores of the University of Washington Center for AIDS Research, an NIH funded program (grant P30-AI-27757), and from the Department of Epidemiology and Biostatistics at the University of Illinois at Chicago. JS received support from grant 1K24 MH093243. The contents are solely the responsibility of the authors and do not necessarily represent the official views of the NIH.

We thank the Director, KEMRI, for permission to publish this work. We thank the Impact Research and Development Organization, as well as the Nyanza Reproductive Health Society for their help with setting up study sites. We also thank Dimagi, Inc. for the software set-up and technical support. We are grateful to the study staff, and the young men of Nyanza province, who are eager to fight the scourge of HIV by undergoing voluntary medical male circumcision.
\end{abstract}

\section{REFERENCES}

1. Auvert B, Taljaard D, Lagarde E, Sobngwi-Tambekou J, Sitta R, Puren A. Randomized, controlled intervention trial of male circumcision for reduction of HIV infection risk: the ANRS 1265 Trial. PLoS Med. Nov.2005 2(11):e298. [PubMed: 16231970]

2. Bailey RC, Moses S, Parker CB, et al. Male circumcision for HIV prevention in young men in Kisumu, Kenya: a randomised controlled trial. Lancet. Feb 24; 2007 369(9562):643-656. [PubMed: 17321310]

3. Gray RH, Kigozi G, Serwadda D, et al. Male circumcision for HIV prevention in men in Rakai, Uganda: a randomised trial. Lancet. Feb 24; 2007 369(9562):657-666. [PubMed: 17321311]

4. Mills E, Cooper C, Anema A, Guyatt G. Male circumcision for the prevention of heterosexually acquired HIV infection: a meta-analysis of randomized trials involving 11,050 men. HIV Med. Jul; 2008 9(6):332-335. [PubMed: 18705758]

5. Gray R, Kigozi G, Kong X, et al. The effectiveness of male circumcision for HIV prevention and effects on risk behaviors in a posttrial follow-up study. AIDS. Mar 13; 2012 26(5):609-615. [PubMed: 22210632]

6. Bailey, RC.; Moses, S.; Parker, CB., et al. International AIDS Society. Vienna: 2010. The protective effect of adult male circumcision against HIV acquisition is sustained for at least 54 months: results from the Kisumu, Kenya trial. 
7. Hallett TB, Alsallaq RA, Baeten JM, et al. Will circumcision provide even more protection from HIV to women and men? New estimates of the population impact of circumcision interventions. Sex Transm Infect. Mar; 2011 87(2):88-93. [PubMed: 20966458]

8. Mehta SD, Gray RH, Auvert B, et al. Does sex in the early period after circumcision increase HIVseroconversion risk? Pooled analysis of adult male circumcision clinical trials. AIDS. Jul 31; 2009 23(12):1557-1564. [PubMed: 19571722]

9. Wawer MJ, Makumbi F, Kigozi G, et al. Circumcision in HIV-infected men and its effect on HIV transmission to female partners in Rakai, Uganda: a randomised controlled trial. The Lancet. 2009; 374(9685):229-237.

10. Hewett PC, Hallett TB, Mensch BS, et al. Sex with stitches: assessing the resumption of sexual activity during the postcircumcision wound-healing period. AIDS. Mar 27; 2012 26(6):749-756. [PubMed: 22269970]

11. WHO/UNAIDS. WHO/UNAIDS Technical Consultation Male Circumcision and HIV Prevention: Research Implications for Policy and Programming. Mar 6-8.2007 2007.

12. WHO/UNAIDS. Operational guidance for scaling up male circumcision services for HIV prevention. 2008. http://whqlibdoc.who.int/publications/2008/9789241597463_eng.pdf

13. Kigozi G, Gray RH, Wawer MJ, et al. The safety of adult male circumcision in HIV-infected and uninfected men in Rakai, Uganda. PLoS Med. Jun 3.2008 5(6):e116. [PubMed: 18532873]

14. Herman-Roloff A, Bailey RC, Agot K. Factors associated with the early resumption of sexual activity following medical male circumcision in nyanza province, kenya. AIDS Behav. Jul; 2012 16(5):1173-1181. [PubMed: 22052231]

15. Thirumurthy H, Lester RT. M-health for health behaviour change in resource-limited settings: applications to HIV care and beyond. Bull World Health Organ. May 1; 2012 90(5):390-392. [PubMed: 22589574]

16. WHO. Knowledge Management. Knowledge management and health. 2012. WHO Department of Knowledge Management and Sharing (KMS). Available at: http://www.who.int/kms/en/

17. mHealth. U.S. Department of Health and Human Services. [Accessed Dec, 2012] Health Information Technology and Quality Improvement. 2012. Available at: http://www.hrsa.gov/ healthit/mhealth.html

18. UNAIDS. Joint strategic action framework to accelerate the scale-up of voluntary medical male circumcision for HIV prevention in Eastern and Southern Africa 2012-2016. Geneva, Switzerland: May 31. 20122011

19. [Accessed 31 May 2012] The world in 2011: ICT facts and figures. 2012. http://www.itu.int/ITUD/ict/facts/2011/index.html2012

20. Lester RT, Gelmon L, Plummer FA. Cell phones: tightening the communication gap in resourcelimited antiretroviral programmes? AIDS. Nov 14; 2006 20(17):2242-2244. [PubMed: 17086071]

21. Lester RT, Ritvo P, Mills EJ, et al. Effects of a mobile phone short message service on antiretroviral treatment adherence in Kenya (WelTel Kenya1): a randomised trial. Lancet. Nov 27; 2010 376(9755):1838-1845. [PubMed: 21071074]

22. Pop-Eleches C, Thirumurthy H, Habyarimana JP, et al. Mobile phone technologies improve adherence to antiretroviral treatment in a resource-limited setting: a randomized controlled trial of text message reminders. AIDS. Mar 27; 2011 25(6):825-834. [PubMed: 21252632]

23. Reback CJ, Grant DL, Fletcher JB, et al. Text Messaging Reduces HIV Risk Behaviors Among Methamphetamine-Using Men Who Have Sex with Men. AIDS Behav. May 19.2012

24. Stockwell MS, Kharbanda EO, Martinez RA, Vargas CY, Vawdrey DK, Camargo S. Effect of a text messaging intervention on influenza vaccination in an urban, low-income pediatric and adolescent population: a randomized controlled trial. JAMA. Apr 25; 2012 307(16):1702-1708. [PubMed: 22535855]

25. Kharbanda EO, Stockwell MS, Fox HW, Andres R, Lara M, Rickert VI. Text message reminders to promote human papillomavirus vaccination. Vaccine. Mar 21; 2011 29(14):2537-2541. [PubMed: 21300094]

26. Free C, Knight R, Robertson S, et al. Smoking cessation support delivered via mobile phone text messaging (txt2stop): a single-blind, randomised trial. Lancet. Jul 2; 2011 378(9785):49-55. [PubMed: 21722952] 
27. Seidenberg P, Nicholson S, Schaefer M, et al. Early infant diagnosis of HIV infection in Zambia through mobile phone texting of blood test results. Bull World Health Organ. May 1; 2012 90(5): 348-356. [PubMed: 22589568]

28. Odeny TA, Bailey RC, Bukusi EA, et al. Text Messaging to Improve Attendance at Post-Operative Clinic Visits after Adult Male Circumcision for HIV Prevention: A Randomized Controlled Trial. PLoS One. 2012; 7(9):e43832. [PubMed: 22957034]

29. Mbuagbaw L, Thabane L, Ongolo-Zogo P, et al. The Cameroon Mobile Phone SMS (CAMPS) trial: a randomized trial of text messaging versus usual care for adherence to antiretroviral therapy. PLoS One. 2012; 7(12):e46909. [PubMed: 23236345]

30. National AIDS and STI Control Programme MoH, Kenya. Kenya National Strategy for Voluntary Medical Male Circumcision October 2009. Nairobi, Kenya: Oct. 2009

31. [Accessed July, 2012] RapidSMS - An open source framework for SMS and Web integrated applications. 2012. http://www.dimagi.com/rapidsms/

32. National AIDS and STI Control Programme MoH, Kenya. Voluntary Medical Male Circumcision Post-Surgery Booklet. 2011. 2013. http://www.malecircumcision.org/resources/documents/ VMMC_post_surgery_booklet.pdf

33. Zou G. A modified poisson regression approach to prospective studies with binary data. Am J Epidemiol. Apr 1; 2004 159(7):702-706. [PubMed: 15033648]

34. Little, Rj; Fau - D’Agostino, R.; D’Agostino, R.; Fau - Cohen, ML.; Cohen, Ml; Fau - Dickersin, K., et al. The prevention and treatment of missing data in clinical trials. 20121004 DCOM-20121016 (1533-4406 (Electronic))

35. Royston P. Multiple imputation of missing values: Update of ice. Stata Journal. 2005; 5(4):527536.

36. Royston P. Multiple imputation of missing values: Further update of ice, with an emphasis on categorical variables. Stata Journal. 2009; 9(3):466-477.

37. Free C, Phillips G, Watson L, et al. The Effectiveness of Mobile-Health Technologies to Improve Health Care Service Delivery Processes: A Systematic Review and Meta-Analysis. PLoS Med. 2013; 10(1):e1001363. [PubMed: 23458994]

38. Car J, Gurol-Urganci I, de Jongh T, Vodopivec-Jamsek V, Atun R. Mobile phone messaging reminders for attendance at healthcare appointments. Cochrane database of systematic reviews (Online). 2012; 7:CD007458.

39. Guy R, Hocking J, Wand H, Stott S, Ali H, Kaldor J. How Effective Are Short Message Service Reminders at Increasing Clinic Attendance? A Meta-Analysis and Systematic Review. Health Services Research. 2012; 47(2):614-632. [PubMed: 22091980]

40. Free C, Phillips G, Galli L, et al. The Effectiveness of Mobile-Health Technology-Based Health Behaviour Change or Disease Management Interventions for Health Care Consumers: A Systematic Review. PLoS Med. 2013; 10(1):e1001362. [PubMed: 23349621]

41. A reality checkpoint for mobile health: three challenges to overcome. PLoS Med. Feb.2013 10(2):e1001395. [PubMed: 23468597]

42. Tomlinson M, Rotheram-Borus MJ, Swartz L, Tsai AC. Scaling Up mHealth: Where Is the Evidence? PLoS Med. 2013; 10(2):e1001382. [PubMed: 23424286]

43. van der Kop ML, Karanja S, Thabane L, et al. In-Depth Analysis of Patient-Clinician Cell Phone Communication during the WelTel Kenya1 Antiretroviral Adherence Trial. PLoS One. 2012; 7(9):e46033. [PubMed: 23049928]

44. Mbuagbaw L, Thabane L, Ongolo-Zogo P. Opening communication channels with people living with HIV using mobile phone text messaging: Insights from the CAMPS trial. BMC Res Notes. Apr 4.2013 6(1):131. [PubMed: 23557081]

45. Odoyo-June E, Rogers JH, Jaoko W, Bailey RC. Factors associated with resumption of sex before complete wound healing in circumcised HIV-positive and HIV-negative men in Kisumu, Kenya. Journal of acquired immune deficiency syndromes (1999). Dec 13.2012

46. Odoyo-June, E.; Rogers, JH.; Jaoko, W.; Bailey, RC. Wound Healing and Resumption of Sex Following Medical Circumcision of Adult Males in Kisumu, Kenya; 16th International Conference on AIDS and STIs in Africa. Abstract \#4312; Addis Ababa, Ethiopia. 2011; 
47. Rogers JH, Odoyo-June E, Jaoko W, Bailey RC. Time to Complete Wound Healing in HIVPositive and HIV-Negative Men following Medical Male Circumcision in Kisumu, Kenya: A Prospective Cohort Study. PLoS One. 2013; 8(4):e61725. [PubMed: 23613918]

48. [Accessed August 31, 2012] Communications Commission of Kenya Quarterly Sector Statistics Report (January-March 2012). 2012. http://cck.go.ke/news/2012/Mobile_Subscribers.html

49. Agot, K.; Ohaga, S.; Ayieko, B.; Omanga, E.; Kabare, M. We too are shareholders: why women must be meaningfully involved in the rollout of medical male circumcision in Africa. Abstract \#MOPDE0107. Presented at: XIX International AIDS Conference; Washington DC, USA. 2012;

50. Odoyo-June, E.; Rogers, JH.; Jaoko, W.; Bailey, RC. Sex before wound healing and condom use among newly circumcised HIV-positive and HIV-negative men in Kisumu, Kenya. Abstract \#MOPE170; Presented at: XIX International AIDS Conference; Washington DC, USA. 2012;

51. Kalichman SC, Pope H, White D, et al. Association between health literacy and HIV treatment adherence: further evidence from objectively measured medication adherence. J Int Assoc Physicians AIDS Care (Chic). Nov-Dec;2008 7(6):317-323. [PubMed: 19056866]

52. Kalichman SC, Catz S, Ramachandran B. Barriers to HIV/AIDS treatment and treatment adherence among African-American adults with disadvantaged education. J Natl Med Assoc. Aug; 1999 91(8):439-446. [PubMed: 12656432]

53. Chi BH, Stringer JS. Mobile phones to improve HIV treatment adherence. Lancet. Nov 27; 2010 376(9755):1807-1808. [PubMed: 21071073]

54. Bennett DA, Emberson JR. Text messaging in smoking cessation: the txt2stop trial. Lancet. Jul 2; 2011 378(9785):6-7. [PubMed: 21722951] 


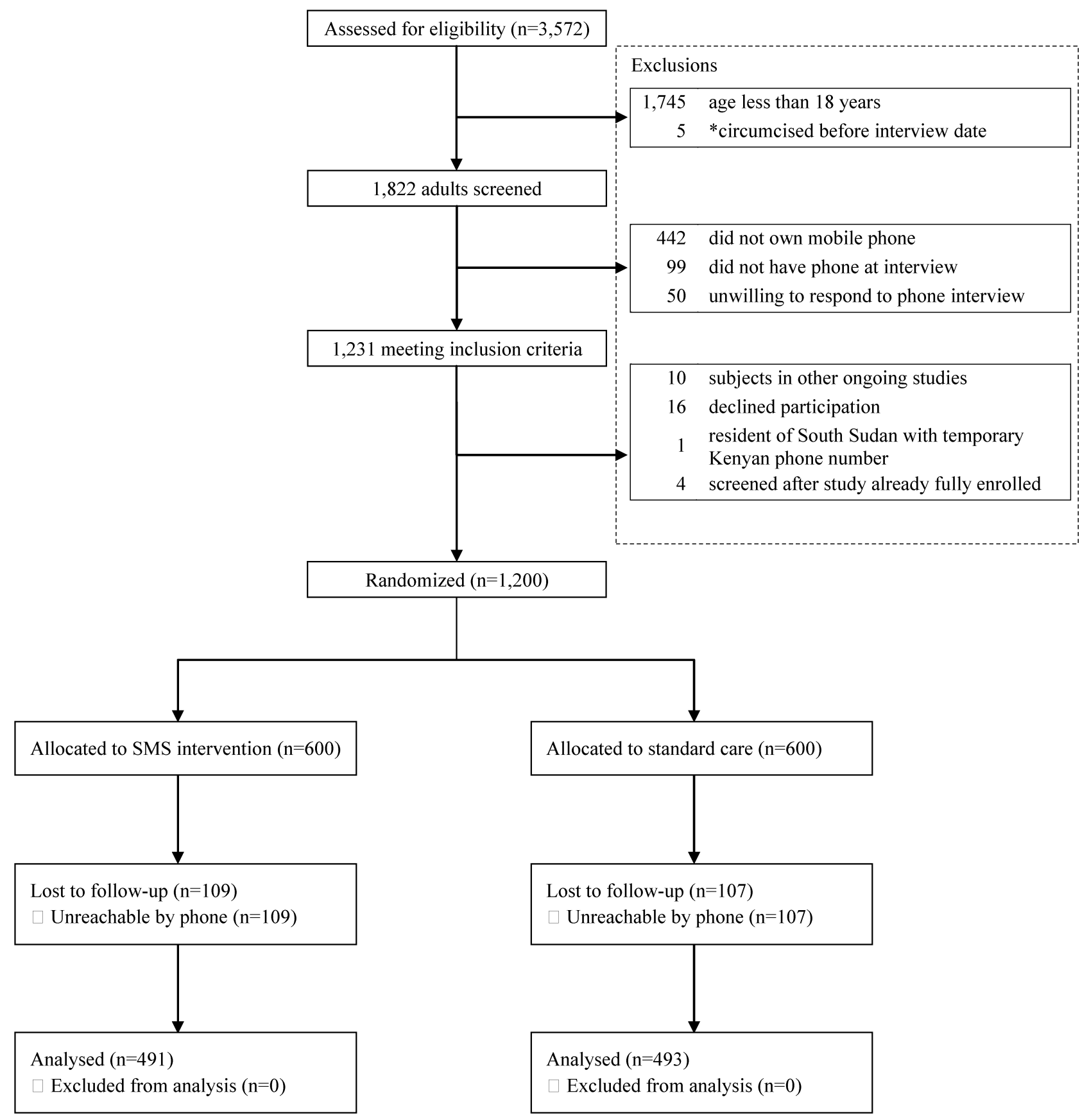

Figure 1. Trial Profile

*The five men circumcised before the interview date were determined to be ineligible at the point of screening and were not included in the study. 


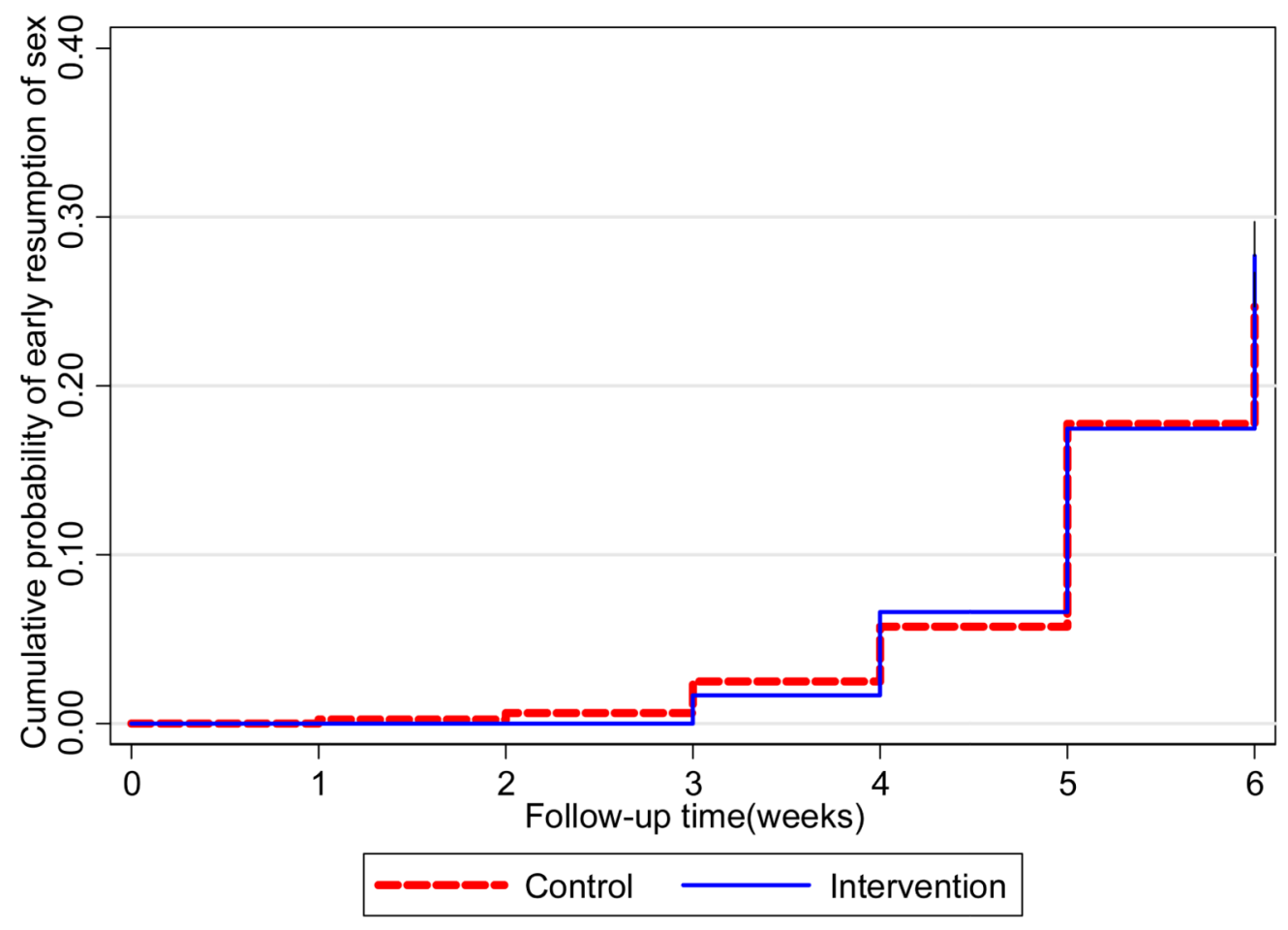

Figure 2.

Kaplan-Meier plot of the cumulative probability of self-reported resumption of sex 


\section{Intervention text messages}

\section{Table 1}

\section{Post-op Messages (English)}

Day

1 If $\mathrm{u} r$ not the intended recipient of this Male Circumcision (MC) message, please text STOP to 0722819835 and you will not receive future messages. Thank you.

1 This is your MC provider. It is normal to feel a bit of pain and swelling, but if there is severe swelling, bleeding or pain please come back to the clinic.

2 This is your MC provider. Remember do not allow water to soak the dressing before removal on the $3^{\text {rd }}$ day.

3 Remove the dressing today. Make sure you review the post-op instructions and use the blade provided. Throw away the blade after use.

4 This is your MC provider. Always keep the genital area dry $\mathrm{n}$ clean to avoid infection. Do not apply any ointment or creams that are not prescribed by the clinic

5 This is your MC provider. If you feel heavy pain, swelling, bleeding, or any signs of infection please consult the clinic.

6 This is your MC provider. Don't forget to come back to the clinic for your day 7 follow-up visit. You will be checked to be certain the healing is going well.

7 This is your MC provider. See you at the clinic today for your follow-up visit.

8 Good things come to those who wait. Remember no sex or masturbation until the end of 6 weeks.

14 This is your MC provider. Be sure to call or come back to the clinic anytime if you have a question or concern.

21 This is your MC provider. Abstaining from sex and masturbation ensures that you will heal properly.

28 This is your MC provider. Remember don't have sex until you are fully healed.

35 Remember that MC does not provide $100 \%$ protection from HIV and STIs.

41 If you start sex after MC, it is important to protect yourself and your partner by using condoms.

42 Remember that MC does not provide $100 \%$ protection from HIV and STIs. Be faithful to one partner and use a condom correctly every time you have sex. 
Table 2

\section{Baseline Characteristics}

\begin{tabular}{|c|c|c|}
\hline Characteristic & $\begin{array}{l}\text { SMS group } \\
(n=491) \\
n(\%)\end{array}$ & $\begin{array}{l}\text { Control group } \\
(\mathrm{n}=493) \\
\mathrm{n}(\%)\end{array}$ \\
\hline \multicolumn{3}{|l|}{ Age group (years) } \\
\hline $18-20$ & $85(17.3 \%)$ & $88(17.8 \%)$ \\
\hline $21-30$ & $277(56.4 \%)$ & $280(56.8 \%)$ \\
\hline $31-40$ & $92(18.7 \%)$ & $79(16 \%)$ \\
\hline$>40$ & $37(7.5 \%)$ & $46(9.3 \%)$ \\
\hline Age (years) - median (IQR) & $25.4(22.0-31.2)$ & $25.14(22.0-31.1)$ \\
\hline Luo ethnic group (versus other) & $469(95.7 \%)$ & $477(96.8 \%)$ \\
\hline Employed (versus unemployed) & $291(59.4 \%)$ & $285(57.8 \%)$ \\
\hline \multicolumn{3}{|l|}{ Number of sex partners in month prior to MC } \\
\hline 0 & $115(23.4 \%)$ & $136(27.6 \%)$ \\
\hline 1 & $307(62.5 \%)$ & $286(58 \%)$ \\
\hline $2+$ & $69(14.1 \%)$ & $71(14.4 \%)$ \\
\hline Ever tested for HIV (versus never tested) & $445(90.6 \%)$ & $450(91.3 \%)$ \\
\hline Condoms offered on day of MC (versus not) & $11(2.2 \%)$ & $6(1.2 \%)$ \\
\hline Age at first sex - median (IQR) & $17.0(15.0-18.0)$ & $16.0(14.0-18.0)$ \\
\hline Travel time to/from clinic (hours) - median (IQR) & $1.0(0.5-1.0)$ & $1.0(0.5-1.0)$ \\
\hline $\begin{array}{l}\text { Transport cost to/from clinic (US\$) - median } \\
\text { (IQR) }\end{array}$ & $0.75(0.5-1.25)$ & $0.63(0.25-1.25)$ \\
\hline Time away from work (hours) - median (IQR) & $3.0(0.0-6.0)$ & $2.0(0.0-6.0)$ \\
\hline Primary or less education & $134(27.3 \%)$ & $131(26.6 \%)$ \\
\hline $\begin{array}{l}\text { Married or living w/sexual partner (versus no } \\
\text { sexual partner) }\end{array}$ & $292(59.5 \%)$ & $282(57.2 \%)$ \\
\hline \multicolumn{3}{|l|}{ Referral source } \\
\hline Self & $338(68.8 \%)$ & $334(67.7 \%)$ \\
\hline Parent & $2(0.4 \%)$ & $4(0.8 \%)$ \\
\hline Friend & $64(13 \%)$ & $83(16.8 \%)$ \\
\hline Voluntary Counselling and Testing & $2(0.4 \%)$ & $2(0.4 \%)$ \\
\hline Community Health Worker & $8(1.6 \%)$ & $6(1.2 \%)$ \\
\hline Other & $77(15.7 \%)$ & $64(13.0 \%)$ \\
\hline
\end{tabular}

$\mathrm{IQR}$, interquartile range; $\mathrm{MC}$, male circumcision 
Table 3

Relative risk regression analysis of predictors of early self-reported resumption of sex

\begin{tabular}{|c|c|c|c|c|c|}
\hline & \multirow{2}{*}{$\begin{array}{c}\text { Resumed sex } \\
\text { early } \\
\text { n }(\%)\end{array}$} & \multicolumn{2}{|c|}{ Unadjusted } & \multicolumn{2}{|c|}{ Adjusted } \\
\hline & & RR [95\% CI] & $p$ value & $\operatorname{RR}[95 \% \mathrm{CI}]$ & $p$ value \\
\hline \multicolumn{6}{|l|}{ Study arm } \\
\hline Control & $124 / 493(25.2 \%)$ & 1 (ref) & --- & $1(\mathrm{ref})$ & --- \\
\hline SMS & $139 / 491(28.3 \%)$ & $1.13[0.91-1.38]$ & 0.3 & $1.09[0.89-1.32]$ & 0.4 \\
\hline \multicolumn{6}{|l|}{ Age group (years) } \\
\hline $18-20 \mathrm{yr}$ & $20 / 173(11.6 \%)$ & 1 (ref) & --- & 1 (ref) & --- \\
\hline $21-30 \mathrm{yr}$ & $144 / 557(25.9 \%)$ & $2.34[1.45-3.46]$ & $<0.001$ & $1.58[1.01-2.47]$ & 0.05 \\
\hline $31-40 \mathrm{yr}$ & $69 / 171(40.4 \%)$ & $3.49[2.22-5.48]$ & $<0.001$ & 1.91 [1.18-3.09] & $<0.01$ \\
\hline$>40 \mathrm{yr}$ & $30 / 83(36.1 \%)$ & $3.13[1.89-5.16]$ & $<0.001$ & $1.76[1.04-2.97]$ & 0.03 \\
\hline \multicolumn{6}{|l|}{ Marital status } \\
\hline $\begin{array}{l}\text { No sexual } \\
\text { partner }\end{array}$ & $59 / 410(14.4 \%)$ & 1 (ref) & --- & 1 (ref) & --- \\
\hline $\begin{array}{l}\text { Married or } \\
\text { living w/sexual } \\
\text { partner }\end{array}$ & $204 / 574(35.5 \%)$ & $2.47[1.90-3.21]$ & $<0.001$ & $1.57[1.18-2.08]$ & $<0.01$ \\
\hline \multicolumn{6}{|l|}{$\begin{array}{l}\text { No. of sex partners in } \\
\text { month prior to MC }\end{array}$} \\
\hline 0 & $34 / 251(13.6 \%)$ & 1 (ref) & --- & 1 (ref) & --- \\
\hline 1 & $179 / 593(30.2 \%)$ & $2.23[1.59-3.12]$ & $<0.001$ & $1.50[1.07-2.12]$ & 0.02 \\
\hline $2+$ & $50 / 140(35.7 \%)$ & $2.64[1.80-3.87]$ & $<0.001$ & $1.81[1.24-2.66]$ & $<0.01$ \\
\hline \multicolumn{6}{|l|}{ Education level } \\
\hline $\begin{array}{l}\text { Secondary or } \\
\text { higher }\end{array}$ & $156 / 719(21.7 \%)$ & 1 (ref) & --- & 1 (ref) & --- \\
\hline Primary or less & $107 / 265(40.4 \%)$ & $1.86[1.52-2.28]$ & $<0.001$ & $1.62[1.33-1.97]$ & $<0.001$ \\
\hline \multicolumn{6}{|l|}{ Employment status } \\
\hline Unemployed & $69 / 407(17.0 \%)$ & 1 (ref) & --- & 1 (ref) & --- \\
\hline Employed & $194 / 576(33.7 \%)$ & 1.99 [1.56-2.54] & $<0.001$ & 1.35 [1.05-1.72] & 0.02 \\
\hline
\end{tabular}

$\mathrm{RR}$, relative risk; SMS, short message service; MC, male circumcision 